\title{
Axial Load Capacity of Cast in Place Piles from SPT and CPTU Data
}

\author{
Ergys Anamali ${ }^{1}$, Neritan Shkodrani' ${ }^{1}$ Luisa Dhimitri² \\ ${ }^{1}$ Departmentof Civil Engineering, Faculty of Civil Engineering, Polytechnic University of Tirana, Tirana, Albania \\ ${ }^{2}$ Department of Geotechnical Engineering, T. T. Soil \& Earthquake Consulting, Tirana, Albania \\ Email: luisadhimitri@insitusi.com
}

Received 5 April 2014; revised 9 May 2014; accepted 16 May 2014

Copyright (C) 2014 by authors and Scientific Research Publishing Inc.

This work is licensed under the Creative Commons Attribution International License (CC BY).

http://creativecommons.org/licenses/by/4.0/

(c) (i) Open Access

\section{Abstract}

This paper aims to deal with the assessment of axial load capacity for cast in place pile foundations, which are made by the earth drill method, by using the data taken from Standard Penetration Tests (SPTs) and Piezocone Penetration Tests (CPTUs). These tests were carried out as part of the investigation program for P.N.G. Terminal-Power Plant, near Semani beach, in Hoxhara marsh, in the western part of Albania. The design of axial load capacity of piles is based on empirical formula using SPT and CPTU values. This study presents the results of axial load capacity analysis of cast in place piles by different analytical calculation methods, which are based on in situ tests results, and also referring to the Building Standard Law of Japan. In the end of our work, differences between calculations methods by using different in situ tests results are shown in tables and graphs.

\section{Keywords}

Cast in Place Pile, Axial Load Capacity, Standard Penetration Test (SPT), Piezocone Penetration Test (CPTU)

\section{Introduction}

The construction site, where the SPT and CPTU tests are carried out, is located in the area of Semani beach, near Fier city, Albania. The tests considered in this study, are executed according to the site investigation program at Terminal Power Plant (here in after referred as P. N. G.) in Seman. A plan of the construction site and the location of in situ tests are shown in Figure 1.

The results of 416 SPT and 12 CPTU are considered during the axial load capacity analysis.

SPT tests were carried out, as the primarily recommended tests for granular soils and other ground conditions 


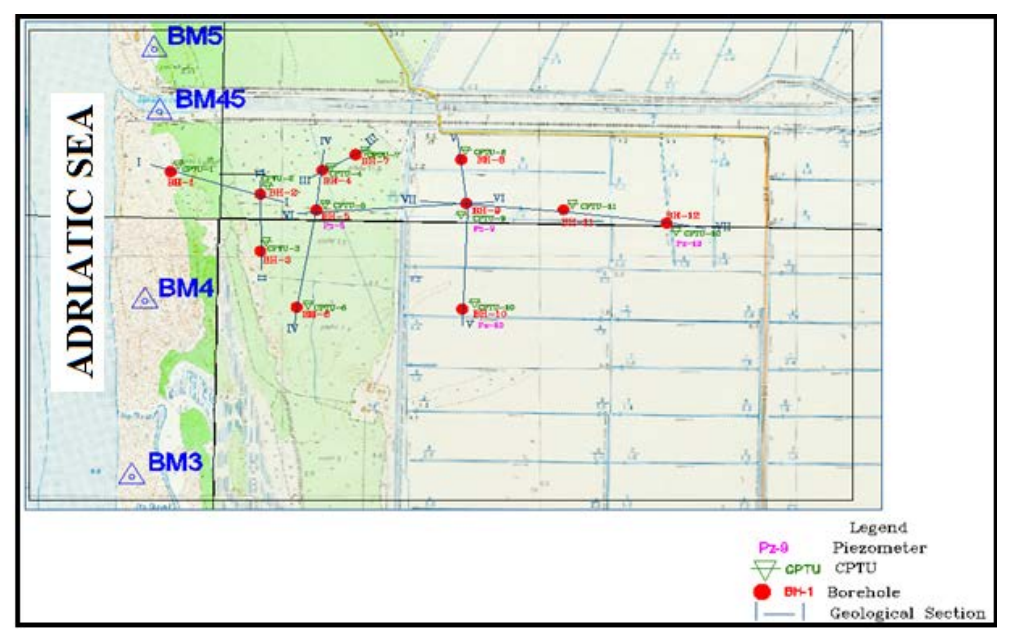

Figure 1. Plan of geological works.

where it is difficult to sample and test in laboratory. This test provides assessments of soils properties and foundation design parameters. It measures the soil resistance to penetration through computation of the number of blows required to drive the sampler $300 \mathrm{~mm}$ into the ground, after it has been advances $150 \mathrm{~mm}$. In recent years the $\mathrm{N}$-value measured by SPT has been subjected to various corrections and is standardized to a reference value of $60 \%$ of the potential energy of SPT hammer [1].

Except SPTs, also CPTUs were performed, because the piezocone test allows the continuous monitoring of the pore pressure, $\mathrm{u}_{2}$, generated during driving, in addition to the electrical measurements of cone tip resistance, $\mathrm{q}_{\mathrm{c}}$, and sleeve friction, $\mathrm{f}_{\mathrm{s}}$. The determination of pile capacity is one of the earliest applications of the CPT data. CPT methods of axial pile capacity calculations generally give superior predictions, because CPT provides a continuous profile of soil and it is still the test that gives the closest simulation to a pile [2].

In this study, deep foundations of type cast in place piles are considered. The depth of pile is kept at a constant value of $20.0 \mathrm{~m}$, meanwhile the diameter varies from $0.5 \mathrm{~m}$ until $2.0 \mathrm{~m}$.

The data taken by Standard Penetration Test (SPT) will be involved in calculations according to O'Neill \& Reese and the Japanese Design Law.

The data taken by Piezocone Tests (CPTU) will be involved in calculations according to Esllami \& Fellenius Method.

All the results will be presented in tables and graphs, so it will be possible to compare the results obtained by different in situ testing techniques.

\section{Axial Load Capacity of Piles by Using SPT}

In this part are described analytical methods used to obtain Ultimate Axial Load Capacity, by using the results of 2 in situ tests, SPT and CPT. Also in this section of the paper, the Japanese Practice of axial load capacity analysis will be presented.

\subsection{Axial Load Capacity from Japanese Method}

The total load capacity of piles is calculated by using Equation (1), where toe bearing resistance and side friction resistance are both considered [3].

$$
P_{a}=\frac{P_{u l t}}{F}=\frac{P_{t}+P_{s}}{F}=\frac{q_{t}^{\prime} A_{t}+\sum f_{s} A_{s}}{F}
$$

where:

$q_{t}^{\prime}=$ net unit toe bearing resistance of pile, which is calculated by the equations given in Table 1

$f_{s}=$ side friction bearing resistance of pile

$A_{t}=$ toe area (normally, the cross sectional area of the pile)

$A_{s}=$ circumferential area of the pile at depth $\mathrm{z}$ 


\section{$F=$ factor of safety}

According to Building Standard Law of Japan the allowable axial load capacity is defined in relation to ultimate axial load capacity, by using a factor of safety $\mathrm{F}=3$, in case of normal conditions. The ultimate bearing capacity of soils is estimated based on geotechnical investigations. The allowable axial load capacity of piles shall be calculated by the equations in paragraph Table 2, in cases when the soil in contact with the pile is a soft clay, or a loose sand, and also in those cases when it is estimated a big liquefaction potential of soils where are driven the piles or are installed the cast-in-place piles [4].

$P_{s}=$ side-friction resistance calculated by the following equation:

$$
P_{s}=\left(\frac{10}{3} \bar{N}_{s} L_{s}+\frac{1}{2} \bar{q}_{u} L_{c}\right) \varphi
$$

$\bar{N}_{s}=$ average percussion frequency (p.s. in our calculation $\bar{N}_{s}$ are equal to $\left(\left(\mathrm{N}_{1}\right)_{60}\right)$ by standard penetration test of sandy ground that is part of the ground around the foundation pile (if it exceeds 30, the value shall be 30).

$L_{s}=$ total length of the foundation pile that is in contact with sandy ground that is part of the ground around the foundation pile.

$\bar{q}_{u}=$ average singly compressive strength of clayey ground that is part of the ground around the foundation pile (if it exceeds 200, the value shall be 200).

$L_{c}=$ total length of the foundation pile that is in contact with clayey ground that is part of the ground around the foundation pile.

$\varphi=$ length of the circumference of the foundation pile [5].

\subsection{0’ Neill and Reese Method for Toe Bearing Resistance}

Analytical design of cast in place piles is based on empirical formulas developed from instrumented full scale static load tests. O' Neill and Reese defined the toe bearing resistance as that which occurs at a settlement of 5\% of the pile diameter. Based on this criterion they recommend computing the net toe bearing resistance in sand with $\mathrm{N}_{60} \leq 50$ as follows [6]:

$$
q_{t}^{\prime}=57.5 N_{60} \leq 2900 \mathrm{kPa}
$$

where:

$N_{60}=$ SPT N-value corrected for field procedures from pile's toe until the depth $2 B_{b}$ under the toe.

$B_{b}=$ diameter in base.

Net unit toe bearing resistance for cast in place piles, with diameter in base bigger than $120 \mathrm{~cm}$, in sandy soils with $N_{60} \leq 50$ according O'Neill \& Reese should be reduced by multiplying with the ratio of $1200 \mathrm{~mm}$ with the diameter in base of the pile. Otherwise a settlements analysis is required.

Table 1. Net unit toe-bearing resistance according to SPT-value [4].

\begin{tabular}{cc}
\hline Category of pile foundation & Allowable unit stress of soil at the tip of the pile foundation \\
\hline Driven pile & $q_{t}^{\prime}=300 \bar{N}$ \\
Bored precast pile made with cement milk method & $q_{t}^{\prime}=200 \bar{N}$ \\
Cast-in-place pile made by the earth drill method, etc. & $q_{t}^{\prime}=150 \bar{N}$ \\
\hline
\end{tabular}

In this table $\bar{N}$ (p.s. in our calculation $\bar{N}$ are equal to $\left(N_{1}\right)_{60}$ shall represent average percussion frequency based on standard penetration test of the ground near the tip of the foundation pile (when it exceed 60, it shall be 60).

Table 2. Formulas for estimation of allowable load capacity of bearing piles [4].

Allowable bearing capacity of ground under internal forces produced by sustained

(1)

$$
P_{a}=\frac{1}{3}\left(q_{t}^{\prime} A_{t}+P_{s}\right) \quad P_{a}=\frac{2}{3}\left(q_{t}^{\prime} A_{\imath}+P_{s}\right)
$$

Allowable bearing capacity of ground under internal forces produced by temporary 
Because of their low hydraulic conductivity, it is assumed that undrained conditions exist in clays beneath the toe of the pile. The net unit toe bearing resistance for piles embeded in clay can be calculated by using the undrained shear strenghth, as given in the Equation (4). O'Neill and Reese reccomend to use in this case the bearing capacity factor, which varies as a function of the undrained shear strength of the soil [6].

$$
q_{t}^{\prime}=N_{c}^{*} s_{u}
$$

where:

$$
\begin{aligned}
& q_{t r}^{\prime}=q_{t}^{\prime} \frac{1200 \mathrm{~mm}}{B} . \\
& N_{c}^{*}=\text { factor of bearing capacity (O’Neill \& Reese). } \\
& s_{u}=\text { undrained shear strength between the pile’s toe and } 2 B_{b} \text { under the pile's toe. }
\end{aligned}
$$

Net unit toe bearing resistance for cast in place piles, with diameter in base bigger than $190 \mathrm{~cm}$, in clayey soils with $s_{u} \leq 250 \mathrm{kPa}$, according O'Neill \& Reese should reduced by using the reduction factor, $F_{r}$, as given by the formula below [5]:

$$
q_{t r}^{\prime}=F_{r} q_{t}^{\prime}
$$

The reduction factor is calculated by Equations (6):

$$
\begin{gathered}
F_{r}=\frac{2.5}{\psi_{1} B_{b}+2.5 \psi_{2}} \leq 1.0 \\
\psi_{1}=0.28 B_{b}+0.083\left(D / B_{b}\right) \quad \psi_{2}=0.065 \sqrt{s_{u}}
\end{gathered}
$$

where:

$D=$ the depth of pile's embedment.

\section{3. $\beta$ Method for Side Friction Resistance}

When using the $\beta$ method the soil is divided into layers, where each layer boundary is located at the soil strata boundaries or at the ground water table. Than is computed $f_{s}$ by the formula given below [6]:

$$
f_{s}=\beta \sigma_{z}^{\prime}
$$

- For cast in place piles embedded in sand, when the value of $N_{60} \geq 15$, O’Neill and Reese recommend the following values for $\beta$ :

$$
\beta=1.5-0.245 \sqrt{z} \quad 0.25 \leq \beta \leq 1.20
$$

where:

$z=$ the depth in the middle of the strata.

Side friction resistance, $f_{s}$, calculated by using the value of $\beta$ is limited until $190 \mathrm{kPa}$.

If $N_{60}<15$, the value of $\beta$ should be mutiplied by the ratio of $N_{60} / 15$.

- For cast in place piles embedded in gravel (gravel grains $>50 \%$ ) Rollins, Clayton and Mikesell recommend the following values for $\beta$ :

$$
\beta=3.4 e^{-0.085 z} \quad 0.25 \leq \beta \leq 3.0
$$

- For cast in place piles embeded in gravelly SAND (gravel grains $25 \%-50 \%$ ) the following values of $\beta$ are recommended:

$$
\beta=2.0-0.15 z^{0.75} \quad 0.25 \leq \beta \leq 1.8
$$

- For cast in place piles embedded in silt or clay the following values of $\beta$ are reccommended by Fellenius:

$$
\beta=0.27-0.50 \text { (Silt) } \quad \beta=0.25-0.35 \quad \text { (Clay) }
$$

\section{Axial Load Capacity of Piles by Using CPT Tests Data}

\subsection{Eslami and Fellenius Method}

Eslami and Fellenius recommend the application of an additional pore water pressure $\mathrm{u}_{2}$ to correct the value of 
effective resistance of cone as follows [6]:

$$
q_{E}=q_{T}-u_{2}
$$

where:

$$
\begin{aligned}
& q_{E}=\text { effective resistance of cone. } \\
& q_{T}=\text { corrected resistance of cone. } \\
& u_{2}=\text { pore water pressure measure at cone tip. }
\end{aligned}
$$

\subsection{Toe Bearing Resistance}

Eslami \& Fellenius method is widely used to correct the net toe bearing resistance, $q_{t}^{\prime}$, with the effective resistance of cone, $q_{E}$. These analysis consider the values of $q_{E}$ only withing the following zones:

$>$ Piles installed through weak soils at the beginning and than passing through compact soils $8 \mathrm{~B}$ above the end of the cone and $4 \mathrm{~B}$ below it.

$>$ Piles installed through compact soils at the beggining than passing through weak soils 2B above the end of the cone and $4 \mathrm{~B}$ below it.

Average value, $q_{E g}$, of $\mathrm{n}$ values $q_{E}$ measured with the defined depth can be calculated as a geometrical average. Net toe bearing resistance, $q_{t}^{\prime}$, should be correlated in empirically manner as shown in Equation (13) [6]:

$$
q_{t}^{\prime}=C_{t} q_{E g}
$$

where:

$C_{t}=$ bearing resistance coefficient $=1$.

$q_{E g}=$ geometric average effective resistance of cone.

\subsection{Side Friction Resistance}

The side friction resistance by using the data of CPT should be calculated by means of Equation (15) [6]:

$$
f_{s}=C_{s} q_{E}
$$

where:

The values of $C_{s}$ depend on soil type and are taken in Table 3. Menawhile soil's classification is done in grapphical way by using the CPT data.

$C_{s}=$ coefficient of side friction.

$q_{E}=$ effective resistance of cone.

\section{Results and Discussions}

Since the analyses of Axial Load Capacity of piles in this construction site are related to the data of SPT and CPTU tests, at first we dialed with the results of these tests, which were reported in the geological study. Average field SPT N-values, corrected SPT $\left(\mathrm{N}_{1}\right)_{60}$-values, average $\mathrm{q}_{\mathrm{c}}$-values and $\mathrm{f}_{\mathrm{sc}}$-values are considered. The geological profiles are constructed for every borehole (12 boreholes in total). In Figure 2, Figure 3 and Figure 4 are given the variances of field SPT N-value, $\mathrm{SPTN}_{60}$-value and field CPTUq $\mathrm{q}_{\mathrm{c}}$-value, $\mathrm{f}_{\mathrm{sc}}$-value with depth for 12 boreholes considered in this paper.

Table 3. Side friction coefficient, $\mathrm{C}_{\mathrm{s}}$ according to Eslami \& Fellenius.

\begin{tabular}{ccc}
\hline Soil Type & \multicolumn{1}{c}{$C_{s}$} & \multicolumn{1}{c}{ Typical Design Value } \\
\cline { 2 - 3 } Soft sensitive soils & Range & 0.08 \\
Clay & $0.0737-0.0864$ & 0.05 \\
Stiff clay or mixture or clay and silt & $0.0462-0.0556$ & 0.025 \\
Mixture of silt and sand & $0.0206-0.0280$ & 0.01 \\
Sand & $0.0087-0.0134$ & 0.004 \\
\hline
\end{tabular}




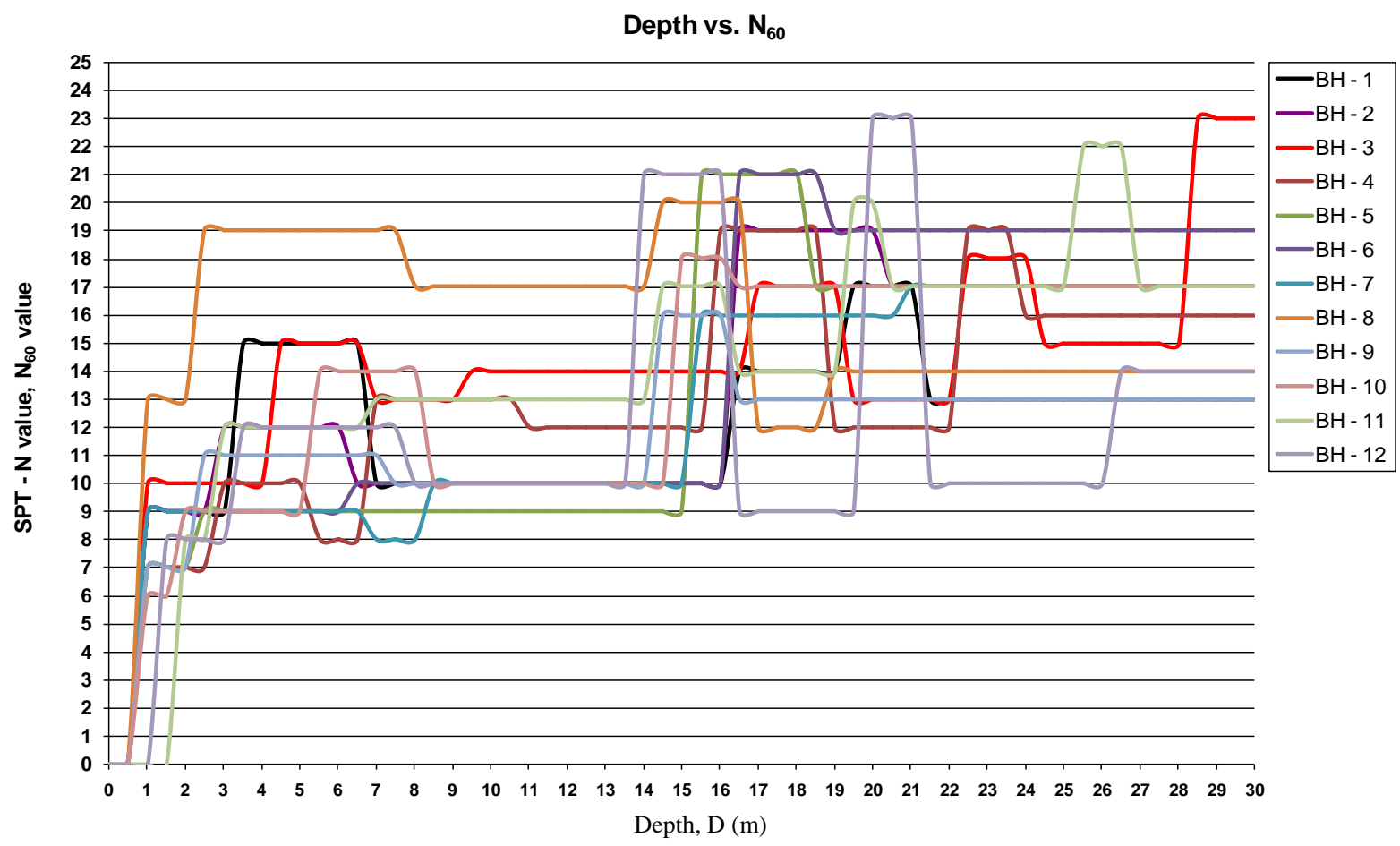

Figure 2. Field SPT N-value, $\mathrm{SPTN}_{60}$ values.

Depth vs. $q_{c}$

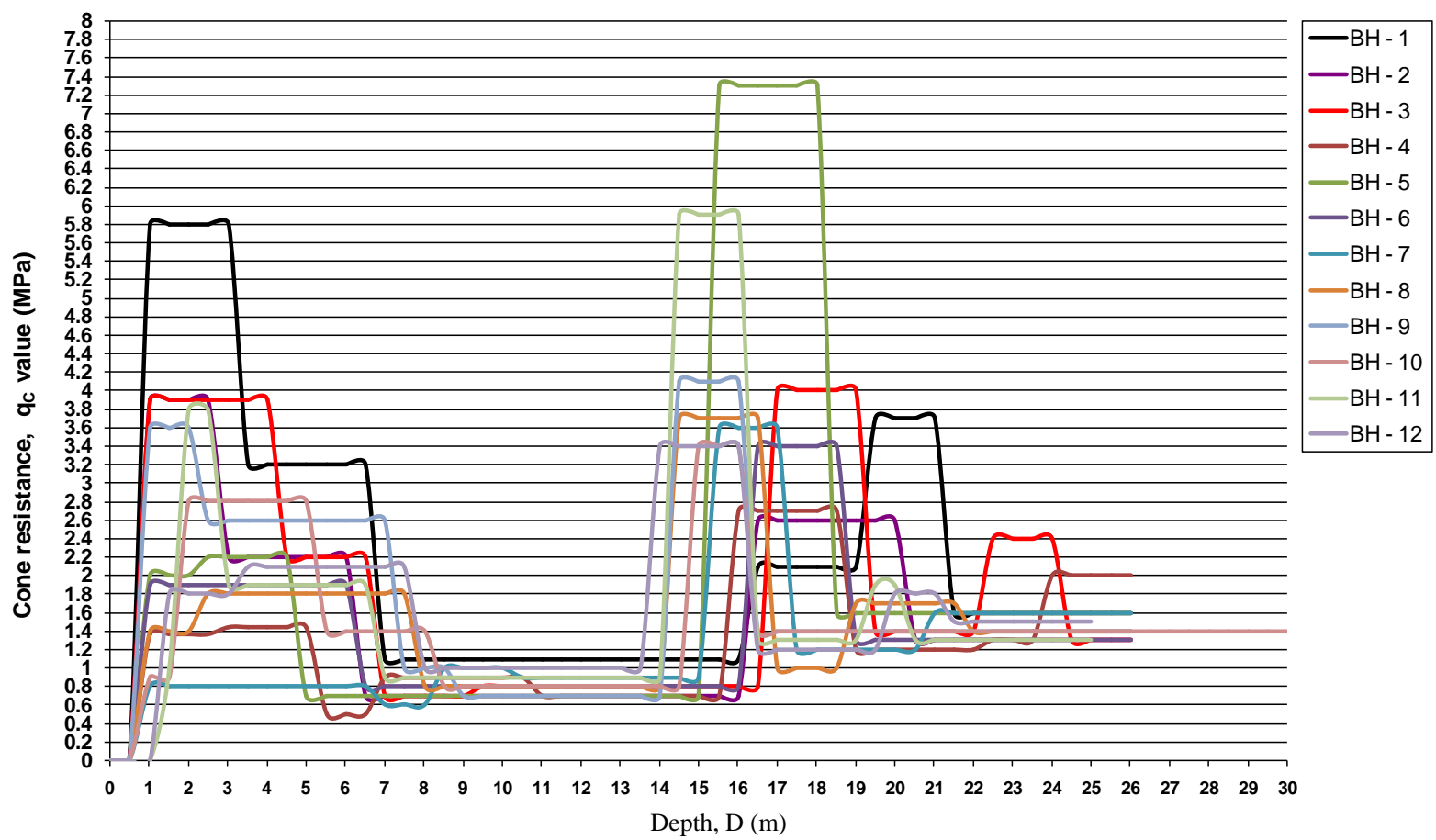

Figure 3. Field CPTUq $\mathrm{c}^{-}$values.

The axial load capacity analyses are performed for each borehole based on the analytical methods already described above.

Considering soil profiles and soil conditions of every borehole, a suitable depth of $20 \mathrm{~m}$ is selected for cast-in- 
place reinforced concrete pile foundations. Pile length is not varied; we have fixed it in a value of $20 \mathrm{~m}$. The considered pile width (pile diameter) is varied in the interval $0.5-2.0 \mathrm{~m}$.

All the results of our geotechnical calculations related to axial load capacity of piles are presented in charts considering various pile diameters (see Figure 5). In these charts, each graph presents axial load capacity related to pile diameter in certain soil conditions which belong to a certain borehole [7].

From the results presented in Table 4, Figure 5 and Figure 6, it is shown that calculated values of axial load capacity based on the SPT, CPTU data and on Japanese practice of design don't differ very much. We see that

Depth vs. $\mathbf{f}_{\mathrm{sc}}$

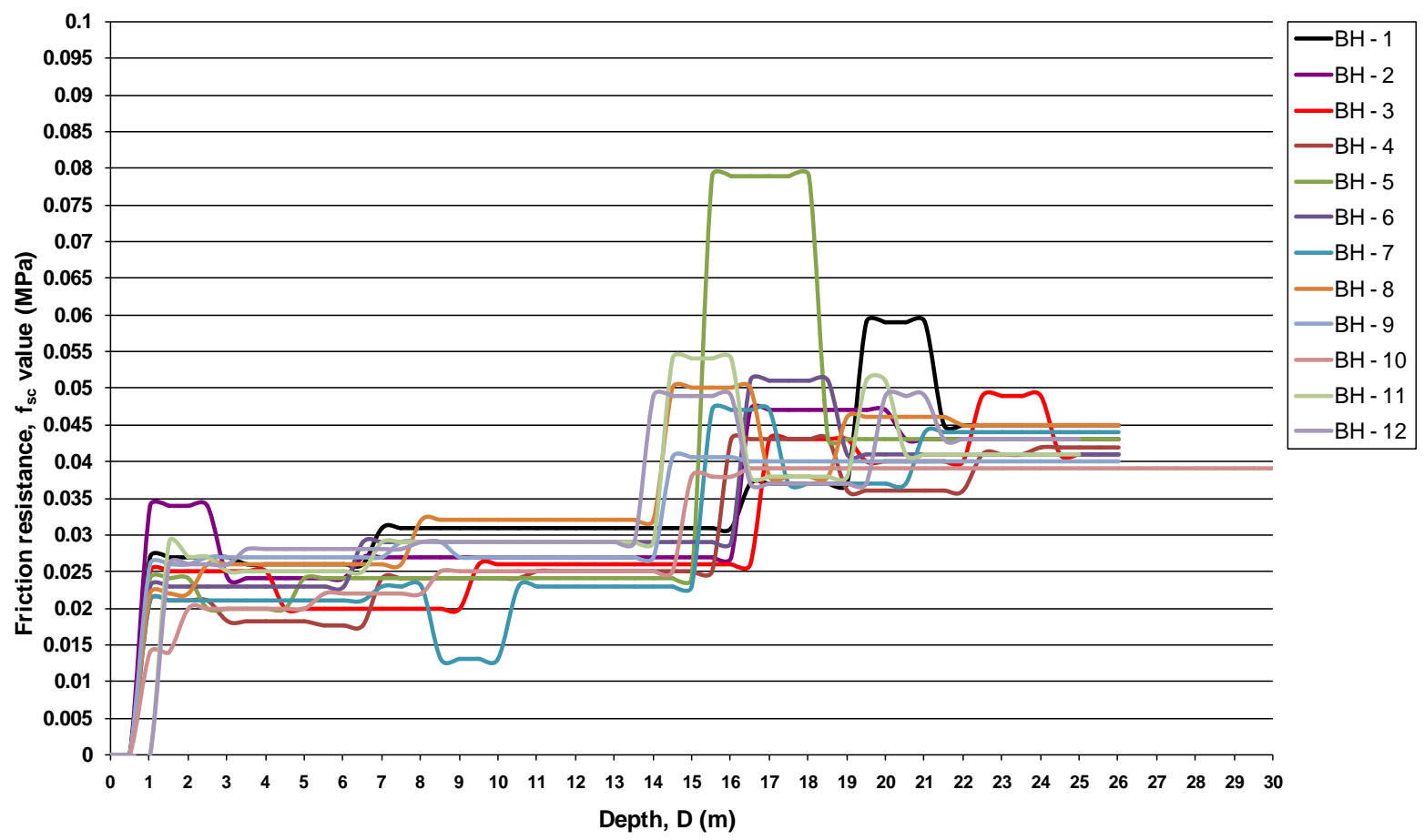

Figure 4. Field CPTUf sc -values.

Table 4. Axial load capacity for cast in place pile foundation $(\mathrm{D}=20.0 \mathrm{~m})$.

\begin{tabular}{|c|c|c|c|c|c|c|c|c|c|c|c|c|c|}
\hline \multicolumn{14}{|c|}{ Table of axial capacity of cast in place pile foundation with $20 \mathrm{~m}$ length, based on 3 methods } \\
\hline \multirow{2}{*}{ Methods } & \multirow{2}{*}{$\mathrm{B}(\mathrm{m})$} & \multicolumn{12}{|c|}{ Axial load capacity $\mathrm{P}_{\mathrm{a}}(\mathrm{kN})$} \\
\hline & & $\mathrm{BH}-1$ & $\mathrm{BH}-2$ & BH - 3 & $\mathrm{BH}-4$ & $\mathrm{BH}-5$ & $\mathrm{BH}-6$ & $\mathrm{BH}-7$ & BH - 8 & $\mathrm{BH}-9$ & $\mathrm{BH}-10$ & BH - 11 & BH - 12 \\
\hline \multirow{4}{*}{$\begin{array}{c}\text { CPT } \\
\text { Method }\end{array}$} & 0.5 & 508 & 256.3 & 191.1 & 168.3 & 254.6 & 166.3 & 144.2 & 237.1 & 222.5 & 177 & 224.1 & 213.1 \\
\hline & 1.0 & 1207 & 639.6 & 536.3 & 432.6 & 603.2 & 428.1 & 400.4 & 566.7 & 561.7 & 456.2 & 549.7 & 542.6 \\
\hline & 1.5 & 1924 & 1179 & 1100 & 850.4 & 1140 & 810.6 & 739.8 & 975.4 & 986.9 & 823.5 & 978.3 & 969.9 \\
\hline & 2.0 & 2681 & 1792 & 1706 & 1446 & 2064 & 1460 & 1267 & 1528 & 1484 & 1203 & 1435 & 1480 \\
\hline \multirow{4}{*}{$\begin{array}{c}\text { SPT } \\
\text { Method } \\
\text { (O’Neil \& } \\
\text { Reese) }\end{array}$} & 0.5 & 396 & o & 385.8 & 41 & 418.9 & 404 & 393.3 & 487.8 & 431 & 421.2 & 464.5 & 515.8 \\
\hline & 1.0 & 870.8 & 889.9 & 827.6 & 882.3 & 921.6 & 896.6 & 867.1 & 1048 & 929 & 928.4 & 1021 & 1150 \\
\hline & 1.5 & 1353 & 1452 & 1325 & 1407 & 1508 & 1478 & 1349 & 1615 & 1494 & 1444 & 1587 & 1796 \\
\hline & 2.0 & 1805 & 1844 & 1714 & 1823 & 1908 & 1858 & 1799 & 2153 & 1920 & 1926 & 2116 & 2394 \\
\hline \multirow{4}{*}{$\begin{array}{c}\text { Japanese } \\
\text { method } \\
\text { (by SPT) }\end{array}$} & 0.5 & 525.8 & 578 & 504.9 & 462.5 & 520.4 & 558.2 & 441.5 & 630.4 & 509.4 & 470.6 & 579 & 539.4 \\
\hline & 1.0 & 1257 & 1379 & 1174 & 1091 & 1277 & 1364 & 1093 & 1449 & 1214 & 1165 & 1405 & 1388 \\
\hline & 1.5 & 2195 & 2404 & 2007 & 1887 & 2270 & 2418 & 1955 & 2456 & 2114 & 2084 & 2476 & 2544 \\
\hline & 2.0 & 3337 & 3652 & 3005 & 2848 & 3499 & 3719 & 3027 & 3651 & 3209 & 3228 & 3793 & 4010 \\
\hline
\end{tabular}



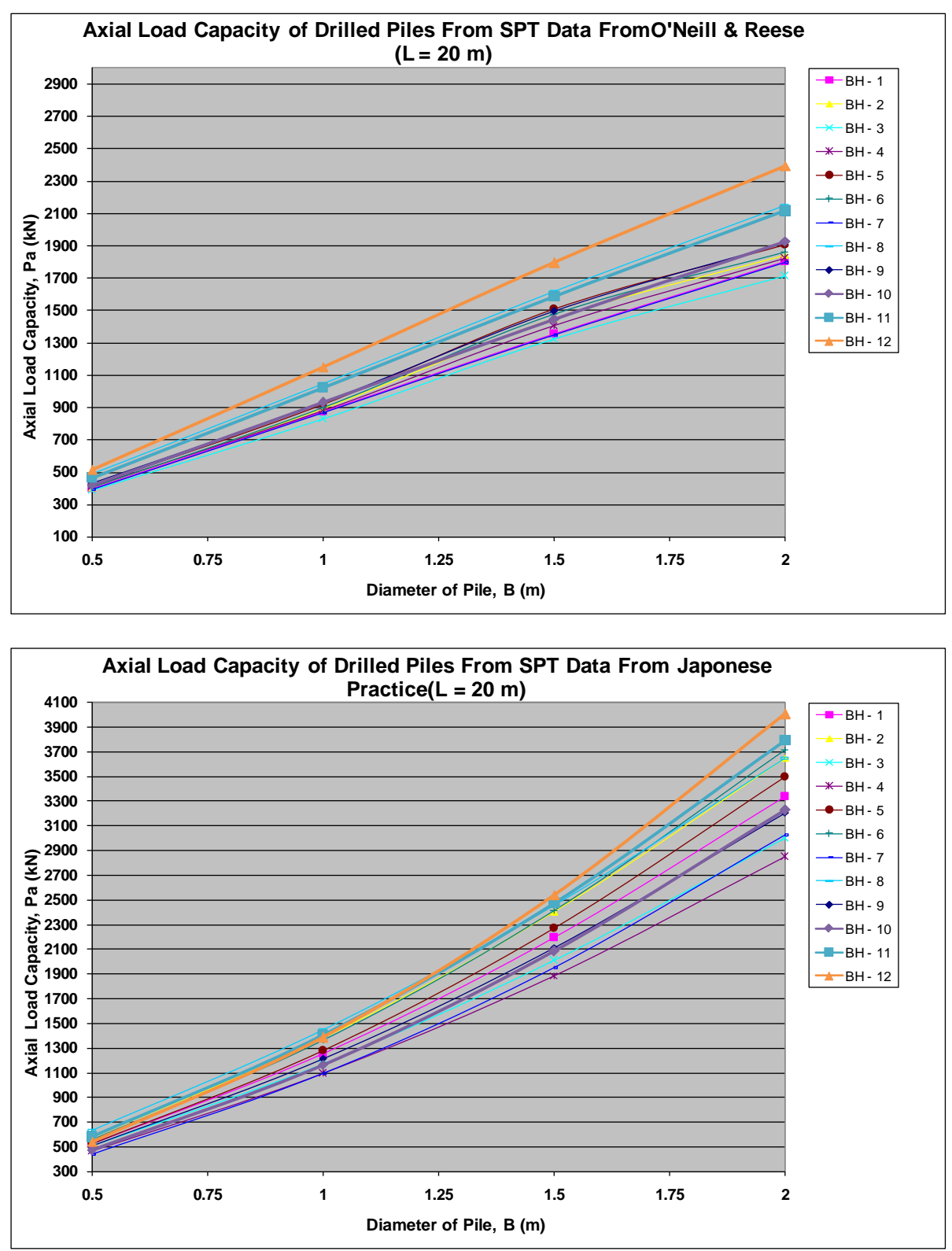

Figure 5. Axial load capacity of cast in place piles by SPT and based calculation methods.

constructed curves in all cases are similar and the gap between them is not significant, especially when the diameter is in the range of $1-1.5 \mathrm{~m}$. We can say that all methods give comparable and consistent results for piles which have the same dimensions and are installed in the same soil surroundings.

\section{Conclusions}

Axial load capacities of piles at P.N.G. Terminal-Power Plant are assessed in this paper. From the results of calculations and discussion of them the below conclusions have resulted from the construction site mentioned above. The axial load in piles varies from one method of calculation to another. According to the SPT based calculations, known as O'Neill and Reese method, the axial load capacities varied from 400 up to $2400 \mathrm{kN}$. According to the Japanese Design Law the results vary from 500 to $4010 \mathrm{kN}$. The results taken by CPT based calculations method and the values of axial mode can be from 500 up to $1480 \mathrm{kN}$.

Maximal axial load capacity is reached according to Japanese Design Law, which is $4010 \mathrm{kN}$. 


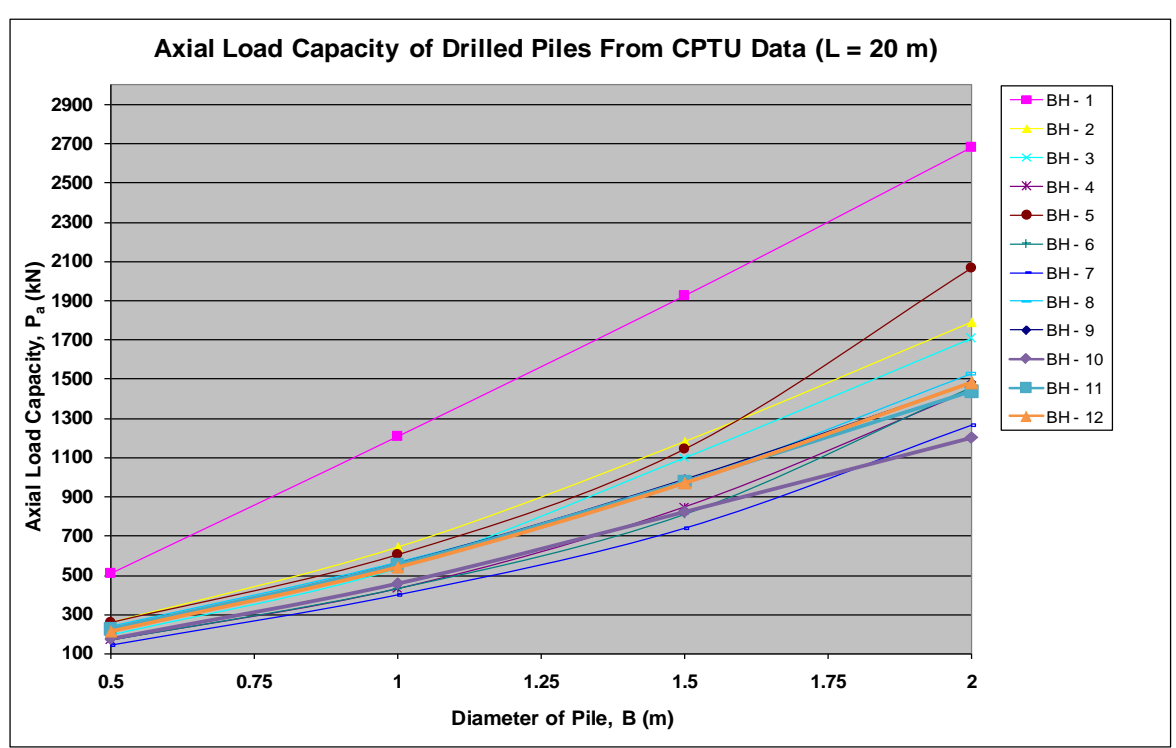

Figure 6. Axial load capacity of cast in place piles by CPT and based calculation methods.

According to the calculation based on CPT results the main important component of total axial load capacity is the toe bearing capacity, determined by the value of $\mathrm{q}_{\mathrm{c}}$ and correlated by $\mathrm{q}_{\mathrm{t}}$.

At BH - 1 the pile's toe is supported by a layer of dense sand. This is the reason that between the other graphs a gap exists in this one. Other piles have almost the same axial load capacity, so the graphs do not create considerable gaps between each others.

Concerning to SPT, it is often noticed that for the same SPT N-value according to two different methods we obtain two different axial loads for pile diameter. This means that the real difference is attributed to toe bearing resistance, because side friction resistance is almost the same in these cases. This is due to different correlations methods of SPT data.

\section{References}

[1] Schnaid F. (2009) In Situ Testing in Geomechanics, 1st Edition, Taylor and Francis, London, New York.

[2] Lunne, T., Robertson, P.K. and Powell, J.J.M. (1997) Cone Penetration Testing in Geotechnical Practice. 1st Edition, E \& FNSpon Press, Abingdon.

[3] Fellenius, H.B. (2009) Basics of Foundation Design. Electronic Edition (The Red Book).

[4] Shkodrani, N. (2012) Dinamika e Pilotave. Parimet Bazedhe Zabtime. 1st Edition, Pegi Publishes, Tirana.

[5] Sugimura, Y., Fujiwara, K., Ohgi, T. and Karkee, M.B. (1997) Seismic Behaviour of Piles Supporting Tall Buildings and the Consideration of Ground Response Effects in Design. Proceedings of the fourth Conference on Tall Buildings in Seismic Regions, Tall Buildings for the 21st Century, Los Angelos, California, Los Angelos Tall Buildings Structural Design Council and the Council on Tall Buildings and Urban Habtat.

[6] Coduto, D.P. (2001) Foundation Design/Principles and Practices. 2nd Edition, Prentice-Hall, Inc., New Jersey.

[7] Shkodrani, N. and Lako, N. (2008) Load Capacity of Piles in Japanese and Albanian Practice of Design. Proceeding of Second British Geotechnical Association International Conference of Foundations, Scotland, 24 June 2008. 